\title{
BONE HEIGHT CHANGES AROUND HYBRID IMPLANTS IN THREE IMPLANT RETAINED MANDIBULAR OVERDENTURES
}

\author{
Eatemad R. Taha* and Azza F. Metwally**
}

\begin{abstract}
Objective: The purpose of this RCL was to evaluate bone height changes around hybrid implants in three implant- retained mandibular overdenture with locator attachment.

Materials \& Methods: Ten completely edentulous male patients were enrolled in this study. Preoperative Cone beam computed tomography (CBCT) had been made to evaluate bone height $\&$ density in areas for implant installation. Patients had received three hybrid implants installed in midline \& mandibular canine areas following flapless technique. Implants were early loaded; two weeks after implant installation. Overdentures were functionally fitted onto the locator attachment of the hybrid implants by direct pick-up technique.
\end{abstract}

Evaluation: Bone height changes were evaluated with the aid of CBCT at the time of implants' loading, six months and twelve months later. Mesial \& distal crestal bone heights were calculated from reconstructed corrected sagittal views.

Results: The results had revealed that there was no significant difference in peri-implant bone level throughout the follow-up periods on comparing the three implant sites. However, there was slightly higher bone resorption around the distal implants than the midline ones.

Conclusions Three implant retained overdentures with locator attachments may preserve periimplant bone in the anterior mandibular area. Midline implant in three implant overdentures may not be subjected to more stresses than the two distal implants

\section{INTRODUCTION}

Completely edentulous patients may be conveniently rehabilitated by Implant-retained overdenture $^{(1)}$. Usually, one to four implants can be used to support a mandibular overdenture between the mental foramina. ${ }^{(2-4)}$ Conventional implant overdenture may rely on two implants at least in the inter-foraminal region ${ }^{(5)}$.

Implant overdenture may help to reduce the anterior ridge resorption rate.Implants may increase the denture retention and stability resulting in increased patient's satisfaction compared to

\footnotetext{
* Associate Professor, Department of Removable Prosthodontics, College of Oral and Dental Surgery, The Canadian Ahram University Egypt.

** Associate professor, Department of Removable Prosthodontics, Faculty of Oral and Dental Medicine, Cairo University, Egypt.
} 
conventional complete dentures. Additionally, overdentures may increase proprioception during speech and mastication with more tongue and facial muscles movement and improved patient confidence ${ }^{(3-7)}$.

The McGill and York $^{(8,9)}$ consensus had suggested that two implant overdenture should be the standard treatment protocol for edentulous mandible. In contrast, Mericske-Stern et al ${ }^{(10)}$ claimed that three or four implants are most suitable for the edentulous mandible, especially in patients with large or V-shaped anterior ridges, to ensure accurate bar designs and favorable overdentures. The authors did not recommend four interforaminal implants because of problems associated with short bars and clips.

Meijer et al ${ }^{(11)}$ suggested that the use of stud attachments, instead of splinted implants with bars, ensures a balanced distribution of stresses. Similarly, Menicucci et al ${ }^{(12)}$ reported that ball attachments transmitted less stress to the implants than a bar/clip design.

A marginal peri-implant bone loss of approximately $1 \mathrm{~mm}$ in the first year and of additional $0.1 \mathrm{~mm}$ annually has been reported as normal in the literature. This rate of bone loss can vary due to unfavorable conditions of masticatory loading and plaque accumulation on the implant sites, which could compromise the prognosis of the oral rehabilitation treatment over the years since it is related to the preservation of the supporting tissues. ${ }^{(13-16)}$

The protection of the osseointegration bond between the implants and living bone from biomechanical failure can be achieved through prediction, reduction and prevention of the biological interface over-stressing. Implant diameter had a more significant effect than implant length to relieve crestal stress and strain concentrations ${ }^{(17)}$. It influences the interfacial stress levels, and the effects of changing implant diameter are significantly noticed more in cortical bone at the crest of the alveolar ridge.

Mini dental implants ranges from1.8 to3 $\mathrm{mm}$. Within the mini implants those with a diameter between 2.7 and $3 \mathrm{~mm}$ are classified as hybrid implants, that combines the advantages of conventional and mini implants. It could be one piece implant to be used with immediate loading protocol or two pieces implant to be used with delayed loading. It is indicated when the buccolingual width of the edentulous ridge is insufficient to place conventional implants ${ }^{(18,19)}$

Locator attachments are now available with hybrid implants. These attachments are selfaligning and have dual (inner and outer) retention mechanism. Locators can be used in patients who have limited inter-arch distance to reduce denture base deformation and fracture due to their low profile. ${ }^{20,21)}$

The number of implants required to provide an adequate mandibular implant overdenture treatment outcome remains debatable. It was pointed out that the value of fewer implants as a cost saving approach has a merit for many patients. However, the use of more than two implants is recommended in certain cases to produce greater overdenture stability and preserving the supporting peri-implant bone ${ }^{(22)}$

The application of three or four implants creates an angular relationship between the implants instead of a straight-line relationship. In the threeimplant-supported overdenture, the most anteriorly positioned implant may provide indirect retention for the denture by preventing the intrusion of the anterior portion of the denture towards the tissues. ${ }^{(23)}$ Such role was believed to increase stresses on the middle implant than other two peripheral implants with subsequent decrease in the marginal bone height. Therefore, this study was conducted to evaluate and compare bone height changes around midline hybrid implant with those around the other two peripheral implants in the three implant- retained mandibular overdenture with locator attachment. 


\section{MATERIALS AND METHODS}

Ten completely edentulous male patients had participated in this study.

Patients having absolute or relative contraindications for implant surgery were excluded.

Maxillary and mandibular complete dentures were constructed for each patient.

Before denture insertion, Mandibular denture was duplicated to construct a diagnostic radiographic stent.

Radiographic stent was constructed from clear acrylic resin with three gutta percha cones placed at the pre-planned implants sites (midline \& mandibular canine areas)

Cone beam computed tomography (CBCT) was performed in the presence of the radiographic stent to assess the bone quantity and quality in the mandibular canine region to allow placement of hybrid implants. Radiographic examination in the selected cases revealed that bone height is more than $14 \mathrm{~mm}$ and bone width not less than $5 \mathrm{~mm}$ in the anterior mandibular region.

The radiographic stent was modified into surgical stent by making holes at the sites corresponding to the implants locations to be used during drilling, which were previously identified by the gutta percha cones.

All patients had signed a written informed consent form to be recruited in the present study.

All patients had received three implants in the mandibular inter foraminal region.

\section{IMPLANTS:}

Three hybrid implants with locator attachment of (2.9 mm diameter \& $12 \mathrm{~mm}$ length) were utilized. (Zest anchors LLC, mini dental implants. Escondido, USA).
Implants were installed in the inter-foraminal region at the pre-planned sites with the aid of the conventional surgical stent, (Fig.2A)

Surgical technique: Flapless surgical technique was conducted for implants placement. Tissue Punch was utilized to remove soft tissues at the proposed implants' sites, through the openings made in the surgical stent. Sequential drilling was then performed according to manufacturer's instructions. Implants were inserted parallel to each other and perpendicular to the occlusal plane with the aid of surgical stent.

Three hybrid implants with locator attachments were inserted; one implant in the mandibular midline $\&$ two implants in the mandibular canine areas.

Locator attachments were covered by plastic protecting covers till the pick-up time. (Fig.2BC).

Patients were not allowed to wear their dentures for few days after surgery; not to interfere with the initial implants' healing process.

Loading protocol: Early loading protocol was conducted in this study; loading of the implants was performed two weeks after surgery

\section{Prosthodontic treatment:}

After 2-weeks period, the tissue surface of the existing mandibualr dentures was excessively relieved opposite to the attachments sites \& around them to allow the patient to use his denture with minimal stresses transferred to the implants.

\section{Pick-up procedures:}

The processing caps were provided into the metal housings and the plastic spacers were placed onto the attachments below the height of contour.

Locator attachments were lubricated with separating medium before positioning the metal housings onto them. 


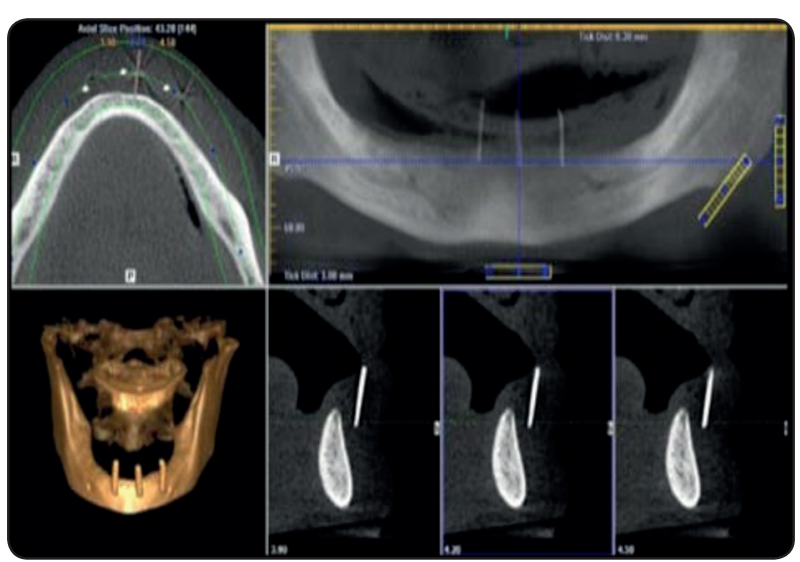

Fig. (1) Diagnostic CBCT with the radiographic stent showing the position of gutta percha cones

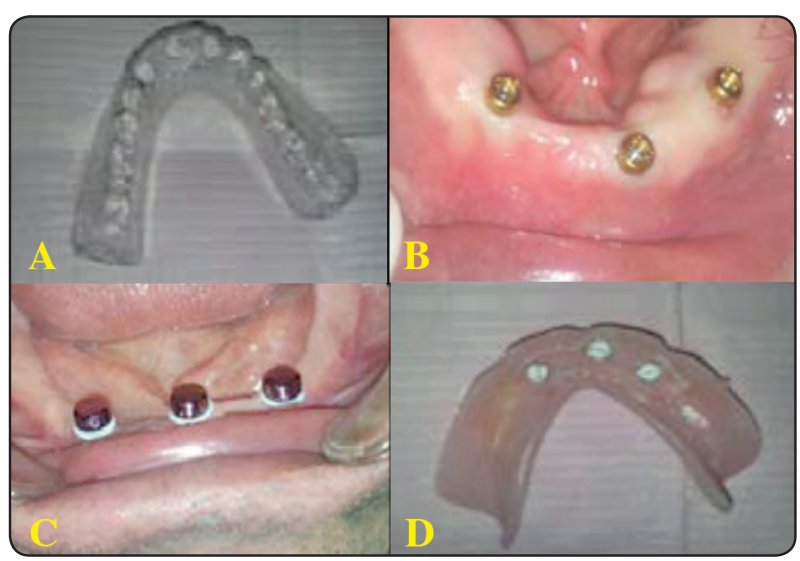

Fig. (2) A) Surgical stent with holes corresponding to implants locations. B) Three hybrid implants with Locator attachments in position. C) Processing caps into the metal housings placed on the attachments. D) Retentive caps of the Locator attachments into the metal housing

Relieved Mandibular overdentures were tried in the patient's mouth to ensure complete seating.

Auto-polymerized acrylic resin (Lucitone 199; Dentsply) was applied in the relieved areas for direct pick-up of the retentive cap and metal housing.

Protective discs were used during pick-up procedures to avoid infiltrations

Patients were instructed to close in maximum inter-cuspal position during curing of acrylic resin.

Once the resin is hardened, the denture was cleaned and polished
Necessary adjustments were carried-out to eliminate any occlusal interference; dentures were delivered to the patients and checked after 24 and 72 hours for any required adjustment.

Patients were instructed to follow strict oral hygiene measures.

\section{Evaluation}

Bone height changes around implants were evaluated with the aid of CBCT

Patients were recalled every month to evaluate their oral hygiene, oral health, peri-implants tissue status, prostheses function and any arising problem.

Bone height changes were evaluated at six and twelve months after denture insertion using CBCT scan, patients were instructed to wear their dentures during radiographic imaging.

CBCT was performed for each patient, at the time of implants' loading, six months and twelve months thereafter. (Fig. 3).

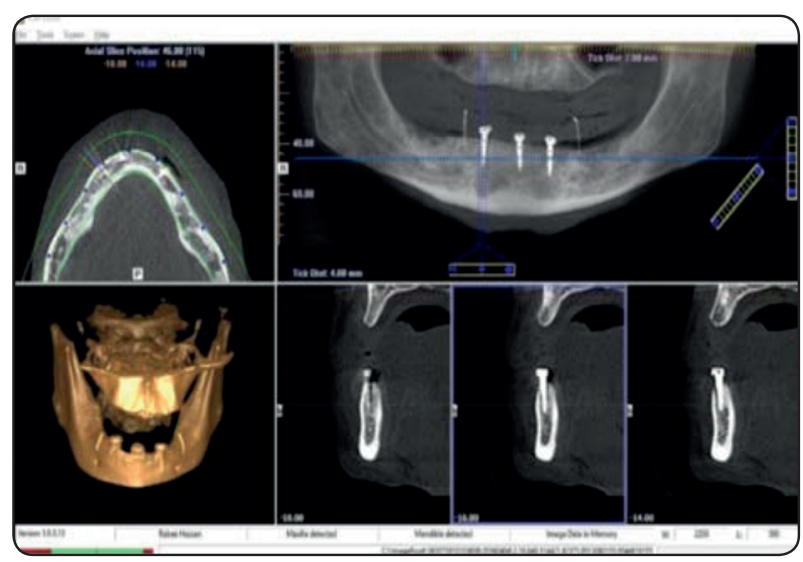

Fig. (3): CBCT showing the three implants with Locator attachments

Mesial and distal crestal bone height changes were calculated from the reconstructed corrected sagittal views by drawing a line parallel to the implant serrations extending from the crestal bone to the apical end of the implant. 
Similarly, labial \& lingual crestal bone height was measured by using cross-sectional views. (Fig. 4).

Average readings of the four sides at each interval were calculated and tabulated for statistical analysis.

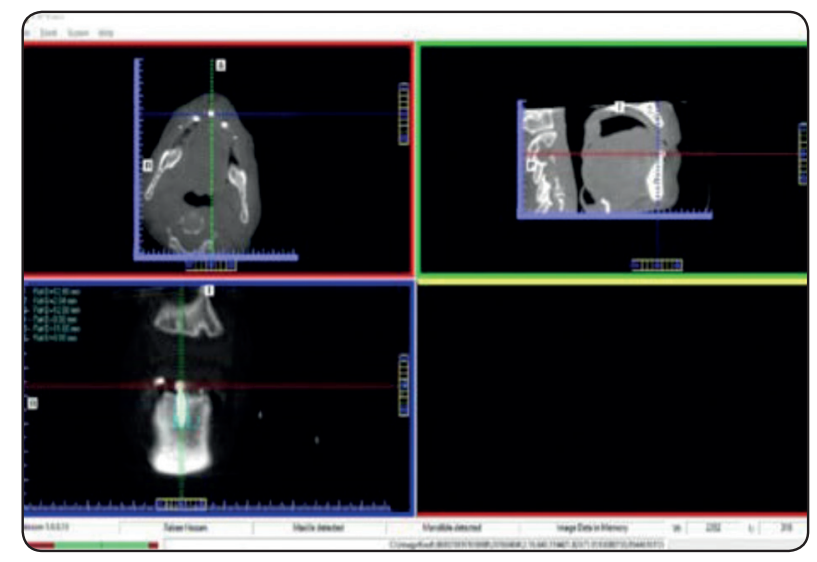

Fig. (4): Peri-implants bone height measurments around the three implants

\section{Statistical analysis}

Data from the three implant sites were collected, tabulated and statistically analyzed and illustrated in tables and figures. Data were summarized as means and standard deviations. Collected data were analyzed using a SPSS statistical package.

One way ANOVA followed by pair-wise Tukey's post-hoc Tests were performed to detect significance between different implant sites. One way ANOVA test was used to compare the change in bone levels around implant at different follow up periods.

The level of significance was set at $5 \%$ for all statistical analyses.

\section{RESULTS}

\section{1- Peri-implant bone level:}

Table (1) and Figure (5) revealed that there were no statistically significant difference $(\mathrm{P}>0.05)$ of peri-implant bone level at different follow-up periods when the three implant sites were compared as indicated by ANOVA test.
However, there was slightly higher bone resorption around the distal implants than midline ones.

TABLE (1) Mean Values and SD for the peri-implant bone level (mm)

\begin{tabular}{|c|c|c|c|c|}
\hline \multirow{3}{*}{ Follow-Up } & Implant Site & Mean & SD & \multirow{2}{*}{ P Value } \\
\hline \multirow{3}{*}{ Baseline } & Right & 11.3 & 0.25 & \multirow{2}{*}{0.88} \\
\cline { 2 - 4 } & Midline & 11.2 & 0.22 & \\
\cline { 2 - 4 } & Left & 11.3 & 0.17 & \\
\hline \multirow{3}{*}{ Months } & Right & 10.82 & 0.19 & \multirow{2}{*}{0.533} \\
\cline { 2 - 4 } & Midline & 10.7 & 0.25 & \multirow{2}{*}{0.72} \\
\cline { 2 - 4 } 12 & Left & 10.9 & 0.20 & \\
\hline \multirow{2}{*}{ Months } & Right & 10.6 & 0.25 & \multirow{2}{*}{0.32} \\
\cline { 2 - 4 } & Midline & 10.5 & 0.32 \\
\cline { 2 - 4 } & Left & 10.6 & 0.15 & \\
\hline
\end{tabular}

$S D=$ standard deviation

$P$ value $<0.05$ show statistically significant

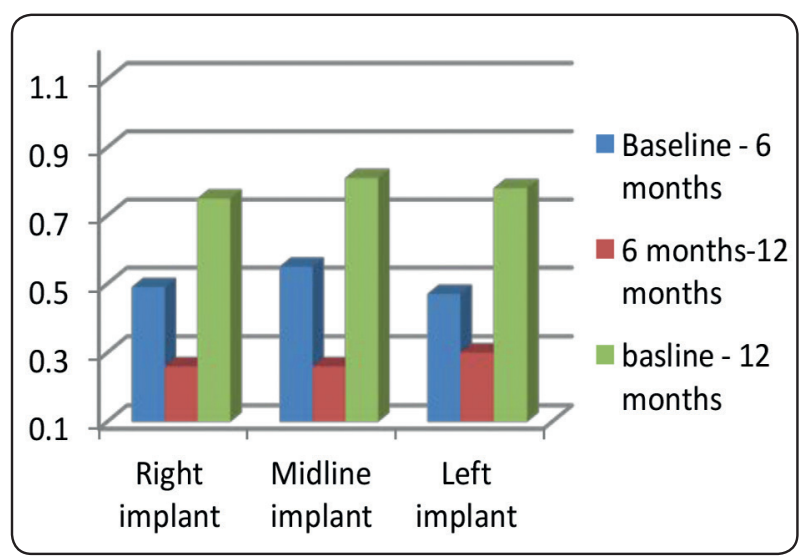

Fig. (5) A bar chart showing the comparison of the Mean Values for the peri-implant bone level ( $\mathrm{mm})$

\section{2- Effect of time on the peri-implant bone level change:}

There were statistically significant difference in the mean values of peri- implant bone level at the different follow-up periods for the three tested implants as indicated by ANOVA test $(\mathrm{P}<0.001)$.

Table2, Fig (6). 
TABLE (2) Effect of time on the peri-implant bone level change:

\begin{tabular}{|c|l|l|l|c|c|c|c|}
\hline implant site & \multicolumn{2}{|c|}{ Baseline -6 Months } & \multicolumn{2}{c|}{ 6Months - 12 Months } & \multicolumn{2}{c|}{ Baseline - 12 Months } & P-value \\
\hline & Mean & SD & Mean & SD & Mean & SD & \\
\hline Right & $0.49^{\text {a }}$ & 0.13 & $0.26^{\mathrm{b}}$ & 0.13 & $0.75^{\mathrm{c}}$ & 0.21 & $<0.001^{*}$ \\
\hline Midline & $0.55^{\mathrm{a}}$ & 0.16 & $0.26^{\mathrm{b}}$ & 0.11 & $0.81^{\mathrm{c}}$ & 0.26 & $<0.001^{*}$ \\
\hline Left & $0.47^{\mathrm{a}}$ & 0.14 & $0.30^{\mathrm{b}}$ & 0.12 & $0.78^{\mathrm{c}}$ & 0.20 & $<0.001^{*}$ \\
\hline p-value & \multicolumn{3}{|c|}{0.62} & \multicolumn{2}{|c|}{0.55} & & \\
\hline
\end{tabular}

\section{Marginal bone level changes}

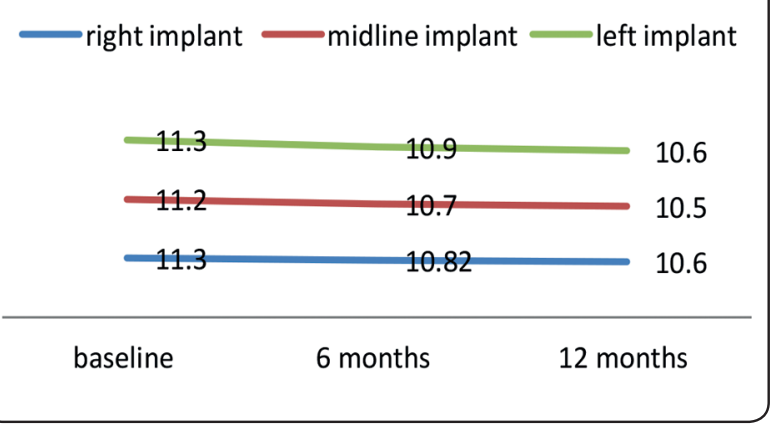

Fig. (6): A linear chart showing the effect of time on the periimplant bone level change $(\mathrm{mm})$

\section{DISCUSSION}

All Patients were satisfied with their implant overdentures; implant retained overdentures had provided the patients better retention, stability, speech, self confidence and masticatory efficiency.

The results of this study had reported crestal bone height loss around the three studied implants throughout the study period.

This bone resorption inevitably occurs around implants in the $1^{\text {st }}$ year of functional loading as reported by many authors who found a mean marginal bone loss around dental implants of 1.5-2 $\mathrm{mm}$ in the first year after prosthetic restoration and 0.1-0.2 mm annually after that ${ }^{(14-17),(24)}$

The recorded mean values of bone resorption around the studied implants were accepted and agreed with the findings of El-Sheikh et.al. ${ }^{(25)}$ who reported favorable bone height, survival rate and prosthodontics maintenance when three, narrow diameter implants with locator attachments are used to retain mandibular over dentures.

Bone resorption may be explained on the basis that, implant overdenture is subjected to masticatory forces. The resultant of these forces is transmitted through the superstructure and attachments to the implants leading to stress concentration in periimplant bone \& consequently bone resorption in those areas.

There are many suggested causes for early implant bone loss. Crestal bone height changes might be attributed to implant loading, concentration of forces, implant placement procedures as well as the possible peri-implant soft-tissue inflammation.

The minor amount of bone resorption reported around implants in the studied design may be attributed to the resilience of the locator attachment which could be an important factor to allow antero posterior movement, laterally and intrusive thus reducing the resultant stresses on the implants and supporting peri-implant bone ${ }^{(21,26)}$.

Elanwar et al, 2017 also supported our finding as they recorded that locator attachment showed less Von Mises stress values than the ball attachment with vertical as well as oblique loading conditions in implant-abutment complex, supporting alveolar bone and the resilient caps. ${ }^{(27)}$ 
They refers this to the low profile design of the locator attachment and to the rotational pivoting character of its abutment that is advocated to lower the rotational center and to potentially reduce the lateral forces. Moreover, using three implants to retain the mandibular overdenture may reduce the stresses on the supporting implants as reported by other researchers ${ }^{(23,24)}$

The insignificant differences of peri-implant bone level between the three studied implants throughout the follow-up periods antagonize the previous concept that the most anteriorly positioned implant provide indirect retention thus increasing the stresses applied on it . However, these findings agree with Liu et al. ${ }^{28)}$ who showed that, in the three-implant-supported overdentures, no strain concentration was found in the cortical bone around the middle implant. They concluded that overdenture anchored by three implants did not cause any strain burden in the cortical bone around the middle implant. They recommend the placement of one-third implant between the original two in patients rehabilitated by two-implant overdentures and report constant and obvious denture rotation around the fulcrum line.

Moreover, in the present study, bone resorption around the distal implants was slightly higher than midline ones. These results may be supported by Geckili et al. ${ }^{(29)}$ who found that the marginal bone loss around the middle implants of threeimplant mandibular overdentures, when using ball or bar attachments, was lower than around the implants on the left and right sides The inevitable movements of the overdentures in distal extension areas around their abutments (implants) may explain this finding.

\section{CONCLUSIONS}

\section{Within the limitations of the present study it may be concluded that:}

Increasing the number of implants may improve the overdenture functions, stability as well as the patient's quality of live.
Three implant retained overdentures with locator attachments may preserve peri-implant bone in the anterior mandibular area.

Midline implants in three implant overdentures may not be subjected to more stresses than the two distal implants.

\section{REFERENCES}

1. Batenburg RH, 1. Meijer HJ, Raghoebar GM, Vissink A. Treatment concept for mandibular overdentures supported by endosseous implants: a literature review. Int J Oral Maxillofac Implants 1998;13:539-45.

2. Jemt T. Implant treatment in elderly patients. Int $\mathbf{J}$ Prosthodont 1993;6:456-61.2.

3. Naert. I, Gizani S, Vuylsteke M, Van Steenberghe D. A 5-year prospective randomized clinical trial on the influence of splinted and unsplinted oral implants retaining a mandibular overdenture: prosthetic aspects and patient satisfaction. J Oral Rehabil 1999;26:195-202.

4. Wright P5. S, Glantz PO, Randow K, Watson RM. The effects of fixed and removable implant-stabilised prostheses on posterior mandibular residual ridge resorption. Clin Oral Implants Res 2002;13:169-74.

5. Walton J6. N, MacEntee MI, Glick N. One-year prosthetic outcomes with implant overdentures: A randomized clinical trial. Int J Oral Maxillofac Implants 2002;17:391-8.

6. Visser 7. A, Meijer HJ, Raghoebar GM, Vissink A. Implant-retained mandibular overdentures versus conventional overdentures: 10 years of case and aftercare. Int J Prosthodont 2006;19:271-8.

7. Ochiai KT, Williams BH, Hojo S, Nishimura R, Caputo AA. Photoelastic analysis of the effect of palatal support on various implant-supported overdenture designs. J Prosthet Dent 2004;91:421-7.

8. Feine JS, Carlsson GE, Awad MA, et al. The McGill Consensus Statement on Overdentures. Montreal, Quebec, Canada,. Int J Prosthodont 2002;15:413-414.

9. British Society for the Study of Prosthetic Dentistry. The York consensus statement on implant-supported overdentures. Eur J Prosthodont Restorative Dent 2009; 17:164-165.

10. Mericske-Stern RD, Taylor TD, Belser U. Management of the edentulous patient. Clin Oral Implants Res 2000;11(suppl 1):108-125. 
11. Meijer HJ, Kuiper JH, Starmans FJ, Bosman F. Stress distribution around dental implants: Influence of superstructure, length of implants, and height of mandible. J Prosthet Dent 1992;68:96-102.

12. Menicucci G, Lorenzetti M, Pera P, Preti G. Mandibular implant retained overdenture: Finite element analysis of two anchorage systems. Int J Oral Maxillofac Implants 1998;13:369-376.

13. Truhlar R8. S, Casino AJ, Cancro JJ. Treatment planning in the elderly implant patients. Dental Clin North Am 1997;41:847-61

14. Jung Y13. C, Han CH, Lee KW. A 1-year radiographic evaluation of marginal bone around dental implants. Int $\mathrm{J}$ Oral Maxillofac Implants 1996;11:811-8.

15. Kitamura 14. E, Stegaroiu R, Nomura S, Miyakawa O. Influence of marginal bone resorption on stress around an implant - a three-dimensional finite element analysis. J Oral Rehabil 2005;32:279-86.

16. Meijer H15. J, Raghoebar GM, Van't Hof MA, Visser A. A controlled clinical trial of implant-retained mandibular overdentures: 10 years results of clinical aspects and aftercare of IMZ implants and Branemark implants. Clin Oral Implants Res 2000;11:441-7.

17. Theodoros T, Konstantinos M, Hiroshi H. Attachment systems for implant retained overdentures. J Impl Dent. 2006; 1: 24-34.

18. Ding X, Liao SH, Zhu XH, Zhang XH, Zhang L. Effect of diameter and length on stress distribution of the alveolar crest around immediate loading implants. Clin Implant Dent Relat Res 2009; 11: 279-287.

19. Faegh S, Muftu S. Load transfer along the bone-dental implant interface. J Biomech 2010; 43: 1761-1770. .

20. Preooteasa E, Imre $M$, Lerner $H$, Tancu AM and Preooteasa C T Emerging Trends in Oral Health Sciences and Dentistry.Narrow diameter and mini dental implant overdentures ; 2015. P.241-264.
21. Evtimovska E, Masri R, Driscoll CF, Romberg E. The change in retentive values of locator attachments and hader clips over time. J Prosthodont 2009; 18: 479-483.

22. Elsyad MA, Errabti HM, Mustafa AZ. Mandibular denture base deformation with Locator and ball attachments of implant-retained overdentures. J Prosthodont 2015: doi:10.1111/jopr.12356. [Epub ahead of print].

23. Sadig W. A comparitive in vitro study on the retention and stability of implant-supported over dentures. Quintessence Int. 2009; 40(4): 313-319.

24. Ben-UrZ, Gorfil C, Shifman A. Anterior implant-supported overdentures. Quintessence International 1996;27:603-6.

25. El-Sheikh AM, Shihabuddin OF, Ghoraba SM. Two versus three narrow-diameter implants with locator attachments supporting mandibular overdentures: a twoyear prospective Int J Dent. 2012;2012:285684.

26. Kurtzman GM. The locator attachment: Free standing versus bar overdentures. Dent Labor Int plus. 2009; 1(1):20-23.

27. El-Anwar, M. I, El-Taftazany, E. A., Hamed, H. A. and Abd ElHay M.A.:Influence of number of implant and attachment types on the stress distribution of mandibular implant-retained overdentures: finite element analysis: Open Access Maced J Med Sci electronic publication ahead of print, published on March 22, 2017 as https://doi. org/10.3889/oamjms.2017.047

28. Liu J, Pan S, Dong J, Mo Z, Fan Y, Feng H. Influence of implant number on the biomechanical behaviour of mandibular implant-retained/supported overdentures: A three-dimensional finite element analysis. J Dent 2013;41:241-9.

29. Geckili O, Bilhan H, Mumcu E. Clinical and radiographic evaluation of three-implant-retained mandibular overdenture: a 3-year retrospective study. Quintessence International. 2011;42:721-8. 